\title{
FORMULASI SEDIAAN MOUTHWASH EKSTRAK ETANOL BUNGAMAWAR MERAH (Rosa damascena Mill) SEBAGAI ANTIBAKTERI TERHADAP Streptococcus mutans
}

\section{FORMULATION OF RED ROSE ETHANOL EXTRACT OF MOUTHWASH (Rosa damascena Mill) AS ANTIBACTERIAL TOWARD Streptococcus mutans}

\author{
Nurfitria Junita*, Nielma Auliah, Wantry Diasny \\ Fakultas Farmasi, Universitas Megarezky Makassar \\ *nurfitriajunita@gmail.com
}

\begin{abstract}
It has been conducted a research about Formulation of Red Rose Ethanol Extract of Mouthwash (Rosa damascena Mill) as Antibacterial toward Streptococcus mutans. This research aim at knowing the activity of Red Rose Ethanol Extract of Mouthwash (Rosa damascena Mill) as Antibacterial toward Streptococcus mutans. In this study, using experimental research by formulating the ethanol extract of red rose (Rosa damascena Mill) mouthwash, then tested against Streptococcus mutans bacteria using the agar diffusion method. The ethanol extract of red rose (Rosa damascena Mill) mouthwash was prepared in three concentrations, namely 1\%, 3\%, 5\%, and control solution. The various concentrations were tested for their antibacterial activity and an evaluation of the Mouthwash by organoleptic observation, $\mathrm{pH}$ and cycling test. Meanwhile, the antibacterial activity test used agar diffusion method using agar well diffusion. Results of the measurement of the largest average inhibition zone at a concentration of $5 \%$ of $21.4 \mathrm{~mm}$. Result showed that physical stability of mouthwash tended to stable on the low temperature storage $\left(4^{\circ} \mathrm{C}\right)$ and had an inhibitory level in strong category in obstructing the growth of Streptococcusmutans.
\end{abstract}

Keywords : red rose flower extract, mouthwash, physical stability, antibacteria, streptococcus mutans

\begin{abstract}
ABSTRAK
Telah dilakukan penelitian tentang formulasi sediaan mouthwash ekstrak etanol bunga mawar merah (Rosa damascena Mill) sebagai antibakteri terhadap Streptococcus mutans. Penelitian ini bertujuan untuk mengetahui aktivitas sediaan mouthwash ekstrak etanol bunga mawar merah (Rosa damascena Mill) terhadap Streptococcus mutans. Pada penelitian ini menggunakan penelitian eksperimen dengan memformulasikan sediaan mouthwash ekstrak etanol bunga mawar merah (Rosa damascena Mill), kemudian diujikan terhadap bakteri Streptococcus mutansmenggunakan metode difusi agar. Sediaan mouthwash ekstrak etanol bunga mawar merah (Rosa damascena Mill) dibuat dengan tiga konsentrasi yaitu 1\%, 3\%, $5 \%$, dan larutan kontrol. Berbagai konsentrasi tersebut diuji aktivitas antibakterinya dan
\end{abstract}


dilakukan evaluasi Mouthwash dengan pengamatan organoleptis, $\mathrm{pH}$ dan Cycling test. Sedangkan pada uji aktivitas antibakteri menggunakan metode difusi agar dengan menggunakan teknik sumuran. Hasil pengukuran rata-rata zona hambat terbesar yaitu pada konsentrasi $5 \%$ sebesar 21,4 mm. Hasil penelitian menunjukkan stabilitas fisik sediaansediaan mouthwash tersebut cenderung stabil pada penyimpanan suhu rendah $\left(4^{0} \mathrm{C}\right)$ dan memiliki daya hambat dengan kategori kuat dalam menghambat pertumbuhan Streptococcusmutans.

Kata kunci : Ekstrak bunga mawar merah, Mouthwash, Stabilitas fisik, Antibakteri, Streptococcus mutans

\section{PENDAHULUAN}

Di Indonesia kesehatan gigi serta mulut merupakan hal yang perlu mendapat perhatian serius oleh tenaga kesehatan, hal ini terlihat bahwa penyakit gigi serta mulut masih diderita $90 \%$ dari masyarakat Indonesia. Adapun yang banyak dialami di Indonesia adalah penyakit jaringan karies gigi (Nurhidayat, Tunggal, dan Wahyono, 2012).

Koloni bakteri yang ditemukan pada awal pembentukan plak adalah bakteri Streptococus mutans. Streptococcus mutans termasuk bakteri gram positif di mana bakteri ini berbentuk lonjong/bulat dengan diameter kurang dari $2 \mu \mathrm{m}$. Koloninya berpasangan/berantai tidak bergerak dan tidak berspora. Metabolismenya secara anaerob dan fakultatif anaerob. Terdapat Streptococcus mutans di dalam plak gigi serta air liur dengan jumlah sangat bervariasi, jumlah ini dipengaruhi oleh berbagai faktor seperti pemberian fluor secara topikal, diet, sukrosa dan penggunaan antibiotik.
Derajat infeksi Streptococcus mutans dipengaruhi jumlah Streptococcus mutans baik komposisi maupun jumlah aliran dan interaksi antar mikroorganisme di dalam plak (Erwana, 2013).

Pencegahan untuk menghambat pertumbuhan bakteri yang menjadi penyebab infeksi dapat dilakukan dengan menggunakan berbagai macam cara, salah satunya adalah dengan berkumur menggunakan Mouthwash (obat kumur). Tujuan pemakaian mouthwash adalah membantu untuk membersihkan rongga mulut yang tidak dapat dijangkau dengan menyikat gigi. Penggunaan obat kumur herbal lebih dianjurkan untuk mengurangi efek samping yang ada, karena pengunaan bahan alami dinilai lebih aman, efek samping lebih kecil dan harganya yang relatif murah (Permatasari, 2014)

Bunga mawar ialah tanaman bunga hias yang memiliki batang berduri, keindahan dan aroma wangi, serta bermanfaat dan memiliki banyak khasiat. (Hariana, 2013). 
Beberapa penelitian yang telah dilakukan menunjukkan aktivitas antimikroba dari bunga mawar. Terdapat kandungan fenol, carvacrol, thymol, dan terpene tinggi pada minyak essensial bunga mawar dimana kandungan fenol dapat membunuh hampir semua mikroba (Mulyana, 2011), kandungan bunga mawar dapat berfungsi sebagai antibakteri, antijamur, antivirus dan antiseptik (Mahmudah, 2015), serta bunga mawar dapat berfungsi sebagai antiseptic dan antijamur karena adanya kandungan geraniol dan limonen didalamnya (Munawarah, 2014). Sedangkan perasan dari bunga mawar bersifat sebagai antibakteri ( Yahya, 2017)

Bila dilihat dari sifat antibakterinya, maka ekstrak bunga mawar dapat dikembangkan dalam bentuk mouthwash (obat kumur) guna mengetahui lebihjauh pengaruh daya antibakteri dari senyawa zat aktif dalam menghambat pertumbuhan bakteri Streptococcus mutans.

Tujuan dari penelitian ini yaitu untuk mengetahui daya aktivitas sediaan mouthwash ekstrak etanol bunga mawar merah(Rosa damascena Mill) terhadap Streptococcus mutans.

\section{METODOLOGI}

\section{Alat dan Bahan}

Alat yang digunakan antara lain alat-alat gelas (Approx dan iwaki), cawan petri, batang pengaduk, handskun, inkubator (Yenaco), jarum ose, jangka sorong, kertas perkamen, lumpang, labu erlenmeyer (Approx), lampu spiritus, oven (Yenoco), penangas air, pipet, pinset, thermometer, timbangan analitik, tabung reaksi (Pyrex), spuit (Terumo), Rotavapor dan sendok tanduk.

Bahan-bahan yang digunakan antara lain etanol,air suling, aluminium foil, $\mathrm{NaCl}$ 0,9\%, kertas saring, bakteri uji (Streptococcus mutans), nutrient agar (NA). Bahan formulasi (ekstrak bunga mawar, tween 80, gliserin, natrium benzoat, dan mentol).

\section{Langkah-langkah Penelitian}

\section{Pembuatan Ekstrak Etanol BungaMawar}

Sampel yang digunakan yaitu bunga mawar merah (Rosa damascena Mill) yang telah kering tanpa pemanasan dari sinar matahari karena pemanasan dengan sinar matahari dapat menyebabkan terjadinya oksidasi pada senyawa yang terdapat pada bunga mawar. Pengeringan pada bunga mawar bertujuan untuk menghilangkan kandungan air pada bunga mawar tersebut. Sampel yang telah kering dihaluskan terlebih dahulu agar dapat 
mempercepat pengeluaran senyawa yang terkandung dalam bunga mawar. Sampel yang telah dihaluskan kemudian diekstraksi dengan metode maserasi selama 3 x 24 jam dengan menggunakan pelarut etanol 70\% sambil sesekali diaduk. Metode maserasi dipilih karena merupakan metode ekstraksi sederhana dan dapat menyari senyawa yang tidak tahan terhadap pemanasan. Maserat yang diperoleh, kemudian disaring untuk memisahkan residu dan filtrat. Lalu filtrat dilakukan pemekatan dengan cara dikipas untuk menguapkan semua pelarut hingga menjadi ekstrak kental. Ekstrak yang telah kental kemudian diletakkan dalam wadah steril kemudian ditutup dengan aluminium foil dan kemudian disimpan ekstrak kental dalam eksikator. Pemekatan bertujuan untuk mengetahui persen rendamen sekaligus mencegah kemungkinan terjadinya kerusakan komponen yang terkandung dalam ekstrak.
Larutan mouthwash dibuat dengan memasukkan ekstrak bunga mawar dan gliserin kelumpang dan digerus hingga homogen. Mentol di masukkan ke lumpang lalu ditambahkan dengan etanol kemudian digerus sampai larut dan dicampurkan kedalam larutan ekstrak etanol bunga mawar. Kemudian ditambahkan natrium benzoat sambil digerus. Lalu ditambahkan tween 80 sedikit demi sedikit dan digerus hingga homogen. Selanjutnya dimasukkan kedalam gelas kimia dan dicukupkan dengan air suling sampai $100 \mathrm{ml}$. Lalu dimasukkan kedalam botol dengan menggunakan kertas saring kemudian wadah ditutup untuk penelitianselanjutnya. Formulasi obat kumur dibagi menjadi 4 formula, formula pertama sebagai kontrol yaitu tanpa ekstrak, formula kedua dengan ekstrak bunga mawar merah dengan masingmasing konsentrasi $1 \%, 3 \%$, dan 5\%.

\section{Pembuatan Formula}

Tabel I. Formulasi sediaan Mouthwash ekstrak etanol Bunga Mawar Merah

\begin{tabular}{|c|c|c|c|c|c|}
\hline No & Bahan & F0 (g) & FI (g) & FII (g) & FIII (g) \\
\hline 1 & $\begin{array}{l}\text { Ekstrak etanol bunga } \\
\text { mawar merah }\end{array}$ & 0 & 1 & 3 & 5 \\
\hline 2 & Na. Benzoat & 0,2 & 0,2 & 0,2 & 0,2 \\
\hline 3 & Menthol & 0,1 & 0,1 & 0,1 & 0,1 \\
\hline 4 & Gliserin & 20 & 20 & 20 & 20 \\
\hline 5 & Tween 80 & 7 & 7 & 7 & 7 \\
\hline 6 & Aquadest ad & 100 & 100 & 100 & 100 \\
\hline
\end{tabular}




\section{Evaluasi Sediaan}

3.1 Pengamatan organoleptis

Penampilan sediaan diamati bau, warna dan kejernihan

\subsection{Pemeriksaan $\mathrm{pH}$}

Nilai $\mathrm{pH}$ diukur menggunakan $\mathrm{pH}$ meter. $\mathrm{pH}$ sediaan obat kumur yang baik ialah mendekati $\mathrm{pH}$ mulut yang netral, yakni $\mathrm{pH}$ 6-7

\subsection{Cycling test}

Sediaan larutan obat kumur disimpan pada suhu $4^{\circ} \mathrm{C}$ selama 24 jam lalu dikeluarkan dan di tempatkan pada suhu $40^{\circ} \mathrm{C}$ selama 24 jam. Perlakuan ini adalah satu siklus. Percobaan diulang sebanyak 6 siklus. Kondisi fisik dan $\mathrm{pH}$ sediaan dibandingkan sebelum dan sesudah uji tersebut

\section{Pengujian aktivitas antibakteri}

Disiapkan medium NA steril lalu dituang $3 \mathrm{ml}$ suspensi bakteri uji kedalam cawan petri, setelah itu medium NA dituang secara aseptis pada cawan petri sebanyak $20 \mathrm{ml}$ sambil digoyanggoyangkan secara teratur sehingga membentuk lapisan yang homogen dan dibiarkan setengah memadat. Dipasang 4

\section{HASIL DAN PEMBAHASAN}

Ekstrak etanol bunga mawar yang diperoleh diformulasikan dalam bentuk sediaan Mouthwash. Kemudian diuji pencadang pada media tersebut dan didiamkan selama beberapa menit agar media tersebut memadat. Dipipet larutan mouthwash yang diuji dari beberapa konsentrasi $\quad(1 \%, \quad 3 \%, \quad 5 \%)$ lalu dimasukkan ke dalam pencadang yang telah terpasang pada media uji hingga pencadang penuh. Dipipet Larutan Kontrol (tanpa ekstrak ) dan dimasukkan ke dalam pencadang yang telah terpasang pada media uji hingga pencadang penuh. Diinkubasi selama 1 x 24 jam pada suhu $37^{\circ} \mathrm{C}$.

\section{Pengamatan dan pengukuran zona hambat}

Pengamatan dilakukan setelah $1 \times 24$ jam masa inkubasi berlaku untuk bakteri. Zonabening merupakan petunjuk kepekaan bakteri terhadap larutan mouthwash bunga mawar atau bahan antibakteri lainnya yang digunakan sebagai bahan uji yang dinyatakan dengan lebar diameter zona hambat. Diameter zona hambat diukur dalam satuan millimeter(mm) dengan memakai jangka sorong. Setelah itu diameter zona hambat tersebut di kategorikan kekuatan daya antimikrobanya berdasarkan penggolongan

aktivitas antibakteri dari formula tersebut terhadap bakteri penyebab karies gigi yaitu Streptococcus mutan. Sediaan 
Mouthwash yang telah dibuat kemudian

fisik sediaan.

dievaluasi untuk mengetahui karakteristik

Tabel II.Hasil Pengamatan Organoleptis sediaan Mouthwash ekstrak etanol bunga mawar merah

\begin{tabular}{|c|c|c|}
\hline Sampel & Pengamatan & Visualisasi \\
\hline \multirow[t]{5}{*}{ Formula 0} & Warna & Bening, tidak berwarna \\
\hline & Bau & Mint, segar \\
\hline & Rasa & Agak manis, mint \\
\hline & Kejernihan & Jernih \\
\hline & $\mathrm{pH}$ & 6,8 \\
\hline \multirow[t]{5}{*}{ Formula I } & Warna & Coklat Kemerahan \\
\hline & Bau & Mint, sedikit bau mawar \\
\hline & Rasa & Agak Manis, mint \\
\hline & Kejernihan & Jernih \\
\hline & $\mathrm{pH}$ & 6,8 \\
\hline \multirow[t]{5}{*}{ Formula II } & Warna & Coklat \\
\hline & Bau & mint, sedikit bau mawar \\
\hline & Rasa & Bau khas mawar, mint \\
\hline & Kejernihan & Jernih \\
\hline & $\mathrm{pH}$ & 6,8 \\
\hline \multirow[t]{5}{*}{ Formula III } & Warna & Coklat Tua \\
\hline & $\mathrm{Bau}$ & Bau khas mawar, sedikit mint \\
\hline & Rasa & Sedikit mint \\
\hline & Kejernihan & Jernih \\
\hline & $\mathrm{pH}$ & 6,8 \\
\hline
\end{tabular}

Berdasarkan tabel II, pemeriksaan organoleptis sediaan, didapatkan sediaan formula tanpa ekstrak yang bening, bau mint, rasa agak manis dan jernih. Pada formula konsentrasi $1 \%$ didapat sediaan berwarna coklat kemerahan, bau mint, rasa agak manis dan jernih. Pada konsentrasi $3 \%$ dan $5 \%$ berwarna coklat, bau mint,agak manis. Perbedaan warna pada formula konsentrasi $1 \%, 3 \%$ dan $5 \%$ disebabkan karena penambahan ekstrak bunga mawar. Pada konsentrasi 1\% berwarna coklat kemerahan karena penambahan ekstrak bunga mawar dalam jumlah yang sedikit yaitu 1 gram sedangakan pada konsentasi 3\% berwarna coklat dan konsentrasi $5 \%$ berwarna coklat tua dan tercium aroma yang khas bunga mawar selain aroma mint, hal ini disebabkan karena pemambahan ekstrak bunga mawar dalam jumlah yang lebihbanyak. Pada pemeriksaan $\mathrm{pH}$ sediaan, didapatkan $\mathrm{pH}$ berkisar antara 67. Hal ini bertujuan agar sediaan mouthwash tidak bersifat asam sehingga dapat menyebabkan korosif pada gigi atau jika bersifat basa dapat mengganggu pengecapan (Rachma, 2010) 
Tabel III.Hasil Pengamatan Cycling Test

\begin{tabular}{|c|c|c|c|}
\hline Sediaan & Pengamatan & Visualisasi & Kristalisasi \\
\hline \multirow[t]{4}{*}{ Formula 0} & Warna & Bening & Tidak \\
\hline & $\mathrm{Bau}$ & Mint & \\
\hline & Rasa & Mint, agak manis & \\
\hline & Kejernihan & Jernih & \\
\hline \multirow[t]{4}{*}{ Formula I } & Warna & Coklat & Tidak \\
\hline & $\mathrm{Bau}$ & Mint & \\
\hline & Rasa & Mint, agak manis & \\
\hline & Kejernihan & Jernih & \\
\hline \multirow[t]{4}{*}{ Formula II } & Warna & Coklat tua & Tidak \\
\hline & $\mathrm{Bau}$ & Mint, bunga mawar & \\
\hline & Rasa & Mint, agak manis pekat & \\
\hline & Kejernihan & Jernih & \\
\hline \multirow[t]{4}{*}{ Formula III } & Warna & Coklat tua pekat & Tidak \\
\hline & $\mathrm{Bau}$ & mint,khas bunga mawar & \\
\hline & Rasa & Mint, agak manis pekat & \\
\hline & Kejernihan & Jernih & \\
\hline
\end{tabular}

Berdasarkan pada tabel III, Pengamatan Cycling test dilakukan untuk mengetahui kemungkinan sediaan mengalami kristalisasi serta untuk menguji kestabilan sediaan (Nurhadi, 2015). Pengujian dilakukan dengan menyimpan masing-masing sediaan pada suhu rendah $\left(4^{0} \mathrm{C}\right)$ selama 24 jam, kemudian dikeluarkan dan ditempatkan pada suhu tinggi $\left(40^{\circ} \mathrm{C}\right)$ selama 24 jam. Perlakuan ini adalah dihitung satu siklus. Percobaan diulang sebanyak 6 siklus untuk memperjelas perubahan yang terjadi (Rachma, 2010). Berdasarkan pengamatan organoleptis keempat formula sediaan obat kumur (mouthwash), tetap stabil dengan tidak ditemukan adanya kristalisasi dan sediaan tetap jernih. Hal ini juga menunjukan kecocokan bahan aktif dan bahan pembantunnya dan menurut (Lachman, 2008) kejernihan juga penting karena suatu cairan yang jelas keruh dengan berjalan waktu tidak dapat diterima. Adapun perubahan warna yang terjadipada sediaan diakibatkan oleh tidak stabilnya minyak atsiri dari bunga mawar, terhadap paparan cahaya serta perubahan suhu yang berubah-ubah. 
Tabel IV. Diameter Zona Hambatan Mouthwash Ekstrak Etanol Bunga Mawar Merah (Rosa damascene Mill) Terhadap Pertumbuhan Streptococcus mutans

\begin{tabular}{c|c|c|c|c|c}
\hline \multirow{2}{*}{$\begin{array}{c}\text { Formula } \\
\text { Konsentrasi }\end{array}$} & \multicolumn{3}{|c|}{ Replikasi } & \multirow{2}{*}{$\begin{array}{c}\text { Rata-rata Daya Hambat } \\
(\mathrm{mm})\end{array}$} & Kategori Daya Hambat \\
\cline { 2 - 4 } & I & II & III & & Kuat \\
$1 \%$ & 17,2 & 17,4 & 17,4 & 17.3 & Kuat \\
$3 \%$ & 19,3 & 19,4 & 19,5 & 19,4 & Sangat Kuat \\
$5 \%$ & 21,4 & 21,3 & 21,5 & 21.4 & Tidak ada \\
\hline KN & 0 & 0 & 0 & 0 &
\end{tabular}

Berdasarkan data pada tabel IV, hasil pengamatan yang diperoleh memperlihatkan bahwa zona hambat yang terbentuk antara semua perlakuan berbeda-beda. Pada perlakuan konsentrasi $1 \%$ diperoleh zona hambat mouthwash ekstrak etanol bunga mawar adalah 17,3 mm. Ini mengindikasikan bahwa konsentrasi $1 \%$ Streptococcus mutans sudah bisa dihambat pertumbuhannya. Hal ini diakibatkan karena banyaknya senyawa yang berperan sebagai antibakteri yang terdapat di dalam ekstrak bunga mawar, senyawa tersebut melalui ikatan nonspesifik membentuk kompleks proteinfenol dengan ikatan yang lemah, terutama geraniol dan citronellol. Kedua senyawa tersebut merupakan senyawa fenol yang berikatan dengan protein pada bakteri serta segera mengalami penguraian. Fenol kemudian merusak membran sitoplasma dan menyebabkan kebocoran isi sel, sehingga pertumbuhan bakteri $S$. mutans pun dapat dihambat. Pada konsentrasi 3\%, $5 \%$ secara berturut-turut diperoleh zona hambat yaitu 19,4 mm, 21,4. Hal tersebut juga mengindikasikan jika semakin tinggi konsentrasi mouthwash ekstrak etanol bunga mawar maka semakin luas zona hambat yang terbentuk. Hasil ini menunjukkan bahwa, seluruh hasil yang diperoleh memiliki kemampuan dalam menghambat pertumbuhan Streptococcus mutans berdasarkan zona hambat yang dihasilkan. Hasil yang diperoleh dalam penelitian ini adalah bahwa mouthwash ektrak etanol bunga mawar pada konsentrasi 1\%, 3\% dan 5\% bersifat kuat dalam menghambat pertumbuhan Streptococcus mutans. Sebagai kontrol, Formula tanpa ekstrak etanol bunga, tidak menunjukkan adanya daya hambat terhadap jamur Streptococcusmutans.

\section{KESIMPULAN}

Berdasarkanhasilpenelitian yang telah dilakukan maka dapat disimpulkan bahwa Formula Sediaan mouthwash ekstrak etanol bunga mawar merah (Rosa damascena Mill)memiliki daya hambat 
dengan kategori sangat kuat dalam menghambat Streptococus mutans.

\section{DAFTAR PUSTAKA}

Erwana, A.F., 2013. Seputar Kesehatan Gigi Dan Mulut. Rapha Publishing.Yogyakarta

Lachman L, Herbert A.L, and Kaning J.L., 2008. Teori dan Praktek Farmasi Industri EdisiKetiga.Penerbit Univeritas Indonesia. Jakarta

Hariana, A, 2013, Tumbuhan Obat dan Khasiatnya, Penebar Swadaya Grup, Jakarta : 72

Mahmudah.N.L .,2015. Enkapsulasi Minyak Mawar (Rosa dasmacena Mill.) Dengan Penyalut $B$ Siklodekstrin Dan B-Siklodekstrin Terasetilasi, http://lib.unnes.ac.id/ 21964/pdf. (Online)

Mulyana, Warya, Fika, dan Inayah., 2011.

Efek Aroma Terapi Minyak Esensial Mawar (Rosa domacena Mill)Terhadap Jumlah Bakteri Udara Ruangan Berpendingin, Medika Planta, 1 (4), 48 -59

Munawaroh.I.R., 2014. Pemberian Relaksasi (Aromaterapi Mawar ) Terhadap Perubahan Tekanan Darah Pada Asuhan Keperawatan Tn. S Dengan Hipertensi Di Ruang Flamboyan RSUD Sukaharjo, http:// digilib. stikeskusumahusada.ac.id /download.php?id=736.pdf,
Dengan konsentrasi terbesar 5\% dengan diameter zona hambat $21,4 \mathrm{~mm}$

(Online)

Nurhadi.G., 2015. Pengaruh Konsentrasi Tween 80 Terhadap Stabilitas Fisik Obat Kumur Minyak Atsiri Herba Kemangi (Ocimum americanum L.), repository.uinjkt.ac.id/dspace/bitst ream/123456789/.../GALIH\%20N URHADI FKIK.pdf (Online)

Nurhidayat, O., Tunggul, E., Wahyono, B., 2012, Meningktakan Pengetahuan Kesehatan Gigi dan Mulut, Unnes Journal of Public Health. Yogyakarta

Permatasari H.C., 2014. Pengaruh Daya Antibakteri Obat Kumur EkstrakEtanol Daun Cuplikan (Physalis anguluta L.) Terhadap Bakteri Streptococcus mutans In Vitro, thesis.umy.ac.id/datapublik/t61941 .pdf, (Online)

Rachma M., 2010. Formulasi Sediaan Obat Kumur Yang Mengandung Minyak Atsiri Temulawak (Curcuma xanthorriza) Sebagai Antibakteri Porphyromonas gingivalis Penyebab Bau Mulut

Yahya I.P., 2017. Uji Daya Hambat Perasan Bunga Mawar (Rosa damascene Mill) Terhadap Pertumbuhan Bakteri Staphylococcus aureus, http://repository.umsurabaya.ac.id/1844/ 